[3] C. L. Siegel, Über die analytische Theorie der quadratischen Formen, Ann. of Math. 36 (1935), pp. 527-606.

[4] G. L. Watson, Integral quadratic forms, Cambridge 1960.

[5] - One-class genera of positive quadratic forms in at least five variables, Acta Arith. $26(1975)$, pp. 309-327.

[6] - Transformations of a quadratie form which do not inerease the class-number, II, ibid., $27\langle 1975\rangle$, pp. 171-189.

[7] - One-class genera of positive ternary quadratic forms - IT, Mathematika 22 (1975), pp. 1-I1.

[8] - The 2-adic density of a quadratic form, ibid., 23 (1976), pp. 94-106.

[9] - The class-number of a positive quadratio form, Proc. London Math. Soc. (3) 13 (1963), pp. 549-576.

[10] E. S. Barnes, The perfect and extreme senary forms, Canad. J. Math. 9 (1957), pp. $235-242$.

UNIVERSITY COLLEGE

London, England

\section{On the existence of a density}

by

Rrero TerRas (La Jolla, Calif.)

We shall give the details which demonstrate a formula for a number theoretical density which played a vital role in our paper [2], but doubts about existence and correctness of the formula have been expressed by A. Garsia, H. Moeller, and the editors. In the meantime Everett [1] has used our encoding idea to derive a new proof for one of our assertions.

We shall recall some of the conventions and symbolisms in our paper. We considered a function $T$, mapping the positive integers into themselves, given by

$$
T n=\left(3^{X(n)} n+X(n)\right) / 2,
$$

where $X(n)=1$ when $n$ is odd and $X(n)=0$ when $n$ is even

Given an integex $n$ we considered iterated partities $n, T n, T^{2} n, \ldots$ $\ldots, T^{k} n$ and we agreed to stop the iteration at the very first instance when $T^{k} n<n$. This stopping time was denoted by $\chi(n)=k$. Infinite values for the stopping time were permitted. We also introduced a second stopping time $\tau(n)$ which had a periodicity property. The quantity $\mathrm{P}[\tau=k]$ was defined to be the proportion of integers in $\left[1,2^{k}\right]$ which satisfy the relation $\tau(n)=k$. The quantities $\mathrm{P}[\tau<k]$ and $\mathrm{P}\left[\tau \geqslant k_{i}\right]$ were defined similarly in the same block of integers.

If $A$ is a set of positive integers then the density of $A$ is defined in terms of the counting function $\mu$ to be

$$
\delta(A)=\lim _{m \rightarrow \infty}(1 / m) \mu\{n \leqslant m \mid n \in A\}
$$

provided this limit exists. We now set $[\chi=k]=\{n \geqslant 0 \mid x(n)=k\}$, and we define $[\tau<k]$ and $[\tau \geqslant k]$ in a similar manner.

Terooner. The denisty of the set $[\chi \geqslant k]$ exists and is given by

$$
\delta[x \geqslant k]=\mathbf{P}[\tau \geqslant k] .
$$

Proof. The trick involved is to get this formula without forming any infinite sums. In [2] we established the formula $\delta[\gamma=k]=\mathrm{P}[\tau=k]$. Finite additivity of density gives $\delta[\chi<k]=\mathbb{P}[\tau<k]$. Since the sets 
$[\chi<k]$ and $[\chi \geqslant k]$ are complementary sets of positive integers one ha that $\delta[x \geqslant k]$ exists and that

$$
\delta[\chi<k]+\delta[\chi \geqslant k]=1 .
$$

One also has the relation

$$
\mathrm{P}[\tau<k]+\mathrm{P}[\tau \geqslant k]=1,
$$

which holds because we have defined the quantities involved in terms 0 a finite block of integers $\left[1,2^{k}\right]$. The assertion of the theorem follows

The relation $\mathrm{P}[\tau \geqslant k]=\delta[\chi \geqslant k]$ enables one to compute explici values of $\delta[\gamma \geqslant k]$ for quite large values of $k$. In [3] we consider tw quite distinct general algorithms in a probabilistic context which enable: one to perform such a computation. A table of these density values alleady appeared in [2].

\section{References}

[1] C. T. Everett, Iteration of the number-theoretic function $f(2 n)=n f(2 n+1$ $=3 n+2$, Advances in Math. 25 (1977), pp. 42-45.

[2] R. Terras,.A stopping time problem on the positive integers, Acta Aritl. 30 (1976) pp. $241-252$

[3] - On some algorithms for computing probabilities (to appear).

\section{Ars Polona, Krakowskie Przedmieście 7, 00-068 Warszawa}

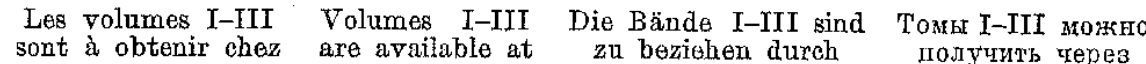

Johnson Reprint Corporation, 111 Fifth Ave., New York, N. Y.

\section{BOOKS PUBLISHED BY THE POLISH ACADEMY OF SOTENOES} INSTITUTE OF MATHEMATICS

S. Banach, Oeuvres, vol. I, 1967, 381 pp.; vol. II, 1979, 470 pp.

S. Mazurkiewicz, Travaux de topologie et ses applications, 1969, $380 \mathrm{pp}$.

W. Sierpiński, Oeurres choisies, ₹ol. I, 1974, 300 pp.; vol. II, 1975, 780 pp.; vol. III, 1976, $688 \mathrm{pp}$.

J. P. Sehauder, Oeuvres, 1978, 487 pp.

\section{MONOGRAFIE MATEMATYCZNE}

27. K. Kuratowski i A. Mostowski, Teoria mnogosci, 5th ed., 1978, $470 \mathrm{pp}$.

41. H. Rasiowa and R. Sikorski, The mathematics of metamathematics, 3rd ed. revised, 1970, $520 \mathrm{pp}$.

43. J. Szarski, Differential inequalities, 2nd ed., 1967, $256 \mathrm{pp}$

44. K. Borsuk, Theory of retracts, $1967,251 \mathrm{pp}$.

45. K. Maurin, Methods of Hilbert spaces, 2nd ed., 1972, $552 \mathrm{pp}$

47. D. Przeworska-Rolewicz and S. Rolewicz, Equations in linear spaces, $1968,380 \mathrm{pp}$.

50. K. Borsuk, Multidimensional analytic geometry, $1969,443 \mathrm{pp}$.

51. R. Sikorski, Advanced caleulus. Functions of several variables, 1969, $460 \mathrm{pp}$

52. W. Slebodziński, Exterior forms and their applications, 1970, 427 pp.

53. M. Krzyżański, Partial differential equations of second order I, 1971, 562 pp.

54. M. Krzyżáski, Partial differential equations of second oder II, 1971, $407 \mathrm{pp}$.

57. W. Narkiewicz, Elementary and analytic theory of algebraic numbers, 1974 , $630 \mathrm{pp}$.

58. C. Bessaga and A. Pelczyński, Selected topics in infinite-dimensional topology, 1975, 353 pp.

59. K. B orsuk, Theory of shape, $1975,379 \mathrm{pp}$

60. R. Engelking, General topology, 1977, 626 pp.

\section{BANACH CENTER PUBLICATIONS}

Vol. 1. Mathematical control theory, $1976,166 \mathrm{pp}$

Vol. 2. Mathematical foundations of computer science, $1977,260 \mathrm{pp}$.

Vol. 3. Mathematical models and numerical méthods, 1978, $391 \mathrm{pp}$.

Vol. 4. Approximation theary, 1979, $314 \mathrm{pp}$.

Vol. 5. Probability theory, in print.

Vol. 6. Mathematical statistics, in print.

Vol. 7. Disorete mathematics, in print.

Vol. 8. Spectral theory, in print. 